\title{
Conference on Arctic Communication
}

\author{
R. C. Kirby and C. G. Little
}

(Received July 23, 1959)

\section{Introduction}

A Conference on Arctic Communication was sponsored by the Central Radio Propagation Laboratory and held at the Boulder Laboratories, National Bureau of Standards, March 3 to 6, 1959. Approximately 275 persons attended, representing universities and research, consulting, and engineering organizations, as well as the Department of Defense and other government agencies. Foreign representation included Canada, Great Britain, SHAPE Air Defense Technical Center, and (by communication) the Norwegian Defence Research Establishment.

The objectives of the conference were to review the results of recent arctic radio research and to discuss current research and operational problems. The opening session was devoted to a review by various laboratories of their arctic research programs. Forty-six papers were then presented at four open and two classified sessions. The conference closed with an informal discussion period, during which three panels, devoted respectively to communication at vlf to lf, hf to vhf, and uhf, discussed fields requiring further research. The full proceedings of the conference will not be published, as it is expected that appropriate papers will be published in technical journals by individual authors.

\section{Review Session}

Dr. C. T. Elvey, Director of the Geophysical Institute, University of Alaska, reviewed the radio propagation research undertaken by the Institute. He first described studies of the scatter and reflection of radio waves at oblique and vertical incidences from the ionosphere. Field strength studies at various frequencies, including some transpolar work between Alaska and Norway, were also described. Dr. Elvey then briefly outlined the application of radio astronomical techniques to the study of ionospheric absorption and scintillation. An experiment involving the use of three Doppler-recording stations on artificial earth satellites, and a new program involving the study of radio wave interaction at frequencies of several megacycles, were also described. This latter experiment is designed to give information on the electron density and electron-collision frequency over the height range 50 to $80 \mathrm{~km}$.

H. S. Marsh described the Air Force Cambridge Research Center's (AFCRC) propagation research program. A number of studies are supported at other research organizations and universities. Four stations are in operation for synoptic studies of transmissions from the oblique sounders at Fairbanks and Thule. In Alaska, ionospheric backscatter techniques are in use to determine electron-density profiles in the ionosphere. AFCRC is also sponsoring a study of low frequency propagation during polar blackouts. Another program is devoted to a study of the literature on arctic propagation, with emphasis on anomalous effects. AFCRC has an "in-house" program to measure the amplitude distribution of high frequency signals received from the Thule backscatter sounder.

A paper summarizing vhf and uhf radar studies of the aurora, in the absence of the authors, R. L. Leadabrand and A. M. Peterson, was read by R. Presnell. The paper reviewed the results of work by several organizations. Topics discussed included position of the aurora in space, strength of the echoes, fading rates, spectra, percent occurrence, polarization, wavelength dependence, and latitude dependence.

The fourth paper, by R. C. Kirby, T. N. Gautier, and A. D. Watt, was a survey of arctic propagation studies at the National Bureau of Standards. The work included NBS-sponsored and other agency programs carried out by the Central Radio Propagation Laboratory. Regular synoptic observations of vertical incidence ionospheric characteristics are made, as well as studies of high frequency field strength, atmospheric noise, very low frequency and low frequency propagation, and ionospheric and tropospheric scattering.

Operational studies of arctic communication problems by the U.S. Army Signal Research and Development Laboratory were described in a paper by C. E. Sharp and A. H. Waite. Investigation of factors affecting transmission ranges of military communication equipment in arctic regions were described.

A report on propagation phenomena observed in operating the DEW line over a 2 -yr period was given by W. Donaldson of the International Telephone and Telegraph Laboratories. Performance of tropospheric scatter, ionospheric scatter, and high frequency communication systems was discussed, including the effects of unusual propagation phenomena, such as ducting at uhf, long range vhf interference, multipath, and backscatter. Propagation phenomena effecting the long range detection by L-band radar were also discussed.

A review of performance of polar region high frequency communication circuits was given by $\mathrm{W}$. R. Vincent, R. L. Leadabrand, and A. M. Peterson, 
of Stanford Research Institute. Logs of selected circuits were analyzed for relation of propagation outage to magnetic disturbances.

The interest of the Voice of America in arctic radio propagation was described by G. Jacobs of the U.S. Information Agency. The operational requirements of the Voice in connection with its worldwide broadcasts were described, as well as methods for bypassing the northern auroral regions. Research sponsored by the USIA includes a visual aurora program and high latitude field strength studies.

Arctic communication experience in the North Atlantic region of the Airways and Air Communication Service was described by Col. W. E. Geyser, USAF. He described the radio communication facilities in the northern regions, including high frequency, low frequency, ionospheric scatter, tropospheric scatter, microwave intersite links, and longline telephone. The operational reliability, flexibility, and limitations of each of these systems was discussed in relation to Air Force requirements. Col. Geyser outlined ultimate communication system requirements and some ideas for a minimum essential communication capability. He stressed the need for a technique which, though possibly severely restricted in information capacity and speed, would offer the highest possible order of propagation reliability and jamming resistance over ranges in excess of 3,000 miles.

Frequency-planning problems for arctic communication were discussed by G. W. Haydon of the Department of the Army. He stressed the lack of basic propagation data for frequency engineering, noting especially the requirements for statistical mapping of absorption in arctic regions and further measurements of noise from aurora. These factors could conceivably become limiting factors as receiver noise figures at vhf and uhf are significantly reduced. He also noted that prediction of high frequency signal strength and noise level were in an unsatisfactory state for arctic regions, and that the zonal concept continued to limit the usefulness of MUF predictions at high latitudes.

F. Lied, director of the Norwegian Defence Research Establishment, communicated a review of ionospheric studies in and near the auroral zone undertaken by that organization. Programs reviewed included studies of forward scatter, drift and fading, auroral reflections, absorption, D-region during blackouts, vlf and lf recordings, hf recordings, and sporadic- $E$ ionization.

The following is the list of papers presented at the review session:

Survey of radio propagation research at the Geophysical Institute, University of Alaska, C. T. Elvey, Geophysical Institute, University of Alaska, College, Alaska.

Survey of Air Force Cambridge Research Center's current long-range propagation research program, H. S. Marsh, Air Force Cambridge Research Center, Bedford, Mass.
A summary of vhf and uhf radar studies of the aurora, R. L. Leadabrand and A. M. Peterson, Stanford Research Institute, Menlo Park, Calif. Survey of NBS arctic propagation studies, R. C. Kirby, T. N. Gautier, and A. D. Watt, Central Radio Propagation Laboratory, National Bureau of Standards, Boulder, Colo.

Signal Corps operational studies of arctic communications problems, C. E. Sharp and A. H. Waite, U.S. Army Signal Research and Development Laboratory, Fort Monmouth, N.J.

ITT report on DEW-line observations, W. Donaldson, IT'T Laboratories, Nutley, N.J.

A review of the performance of polar region communications circuits, W. R. Vincent, R. L. Leadabrand, and A. M. Peterson, Stanford Research Institute, Menlo Park, Calif.

The Voice of America's interest in arctic radio propagation, G. Jacobs, U.S. Information Agency, Washington, D.C.

Arctic experience of NORLAN'T A.ACS and systems limitations, Col. W. E. Geyser, Headquarters North Atlantic AACS Region, USAF, Westover AFB, Mass.

Frequency engineering problems in arctic communications, G. W. Haydon, Office of Chief Signal Officer, Department of the Army, Washington, D.C.

Ionospheric studies in and near the auroral zone undertaken by the Norwegian Defence Research Establishment (communication from F. Lied, director, Norwegian Defence Research Establishment, Oslo, Norway).

\section{Classified Sessions}

Two classified sessions were held. Representatives of Army, Navy, and Air Force described operational plans and requirements, and classified results of research programs were presented.

Requirements of the Strategic Air Command and arctic communication experience of that organization were discussed by Col. C. W. Bagstad, Headquarters, SAC, Offutt AFB, Nebr. A discussion of USAF future communication requirements was given by Col. T. N. Dickens, and a description of plans for fulfilling these requirements was given by Col. H. R. Johnson. Both represented Headquarters, USAF.

A further Air Force study of air/ground communication requirements in arctic regions for air defense systems was reported by Maj. W. Athas of the Air Defense Systems Integration Division and J. F. Roche of Lincoln Laboratory, Massachusetts Institute of Technology.

The Navy's communication requirements in polar regions were discussed by J. L. Harris, Office of the Chief of Naval Operations, Navy Department.

Army operational requirements for communication in the Aretic were described by A. Brown of the U.S. Army Signal Research and Development Laboratory at Fort Monmouth. 
A study by SHAPE of ship/shore communication problems in the North Atlantic was reported by Dr. N. Knudtzon, Chief of the Communications Group, SHAPE Air Defense Technical Center, The Hague, Netherlands.

A special study of arctic vlf propagation, involving transmission over ice, was reported by A. G. McNish of the National Bureau of Standards.

The status of an experimental study of the usefulness of scatter propagation for air/ground communication was reported by T. F. Rogers on behalf of the Air Force Cambridge Research Center.

Arctic tropospheric scatter results were discussed in two presentations. A description of DEW DROP, "a link between Thule and Omaha," and its operational performance was given by Glen Mellen of the Massachusetts Institute of Technology. Tropospheric scatter in the arctic over high altitude paths was discussed by A. E. Teachman of Page Communication Engineers, Inc.

\section{Open Technical Sessions}

Twenty-two papers were presented during three open technical sessions. Abstracts are reproduced below, in alphabetical order by first author.

\section{HF Field Strength Measurements in the Arctic}

V. L. Agr, Central Radio Propagation Laboratory, National Bureau of Standards, Boulder, Colo.

High frequency $\mathrm{cw}$ transmissions on 7.815 and 10.905 Mc from Bismarck, N.Dak., and Maui, Hawaii, were recorded at Anchorage and College, Alaska, using narrow-band receivers, for the period from about April 1, 1958 to December 31, 1958. In spite of the narrow bandwidth of the receivers, interference rom stations on or near $10.905 \mathrm{Mc}$ rules out the use of recordings at this frequency for detailed comparions. The $7.815-\mathrm{Mc}$ recordings, for the most part, lowever, have been satisfactory.

For the period covered by the recordings the folowing conclusions may be drawn:

1. The paths from Bismarck (Bismarck-Anchorge, Bismarck-College) are not notably different rom a propagation standpoint. Certainly the large ifferences in field strength expected on the basis of ,n assumed sharply defined auroral absorption zone more or less coincident with the visual auroral zone) o not occur.

2. Correlations exist between field strength variaions observed over any pair of the four paths (Bissarck-Anchorage, Bismarck-College, Maui-Anchorge, and Maui-College) which are in general much arger than those observed for propagation paths ntirely free of auroral zone effects.

3. Distributions of field strength values for the ismarck paths for nighttime hours have an interecile range of around $30 \mathrm{db}$, while for the Maui aths the interdecile range is about $15 \mathrm{db}$. This ifference is attributed to auroral zone attenuation fects.
4. In addition, after correction for differences in transmitter power and path length, a median difference in field strength (Maui minus Bismarck) at either receiver of about $15 \mathrm{db}$ can be ascribed to auroral zone absorption.

\section{Abnormal Ionization in the Lower Ionosphere Associated With Cosmic-Ray Flux Enhancements}

D. K. BaIley, Page Communications Engineers, Inc., Washington, D.C.

Abnormal ionization in the lower ionosphere associated with cosmic-ray flux enhancements is discussed mostly in terms of the great solar event of February 23, 1956. Two kinds of abnormality were recognized: Early effects observable in the dark hemisphere at the time of the sudden cosmic-ray enhancement, and late effects which began gradually and reached a maximum a few hours after the cosmicray enhancement. The late effects died away over a period of several days in geomagnetic latitudes above $70^{\circ}$, but more rapidly in lower latitudes. Both effects were more intense in higher geomagnetic latitudes. Early effects, though much the less intense of the two, appear to have been observable in lower geomagnetic latitudes than were the late effects.

The early effects are explained as a consequence of a plausible difference in composition between streams of solar particles of cosmic-ray energies and ordinary cosmic rays. The late effects are explained in terms of ionization produced in the lower ionosphere (the range of height from 30 to $110 \mathrm{~km}$ is studied) by the passage or stopping of solar particlesmostly protons. Such particles are shown, like the more energetic solar cosmic rays, to be arriving essentially isotropically after the maximum effects occur. A plausible extension of the observed magnetic-rigidity spectrum of the solar cosmic rays downward in rigidity by about a power of 10 would provide the protons necessary to account for the observations. The absence of auroral and significant magnetic activity accompanying the abnormal ionization is consistent with the explanations offered. Moreover, certain more recent high-latitude absorption events, unaccompanied by groundlevel cosmicray flux enhancements, are explicable in similar terms.

An interesting by-product of the investigation is a provisional evaluation not only of the coefficient of collisional detachment of electrons from negative ions, probably mostly $\mathrm{O}_{2}^{+}$, but also of the negativeion-to-electron ratio and the effective recombination coefficient at night between 30 and $110 \mathrm{~km}$.

\section{Predicting the Performance of Long Distance Tropospheric Communication Circuits}

A. P. Barsis, K. A. Norton, and P. L. Rice, Central Radio Propagation Laboratory, National Bureau of Standards, Boulder, Colo.

Performance of long-distance tropospheric communication circuits is predicted in terms of the prob- 
ability of obtaining a specified grade of service or better for various percentages of the time. The grade of service is determined by the minimum acceptable ratio of hourly rms carrier to rms noise for the type of intelligence to be transmitted. It is shown that the prediction errors, expressed in decibels, have a standard deviation which depends upon the percentage of hours the specified grade of service is required and on the angular distance characterizing the propagation path. Finally, the possibility of reducing this standard deviation by making path-loss measurements is discussed. Thereby the reliability of the prediction might be increased.

As the prediction uncertainty was determined from analysis of a great amount of propagation data representing a variety of climatic regions, and the initial determination of basic transmission loss for any propagation path involves the use of meteorological parameters for the area concerned, the prediction method is equally applicable to arctic communication problems. Calculation schemes and graphical aids have been prepared which enable the practicing engineer to use the prediction method for any particular communication link.

\section{Climatological Effects on Radio Propagation}

B. R. Bean, Central Radio Propagation Laboratory, National Bureau of Standards, Boulder, Colo.

The National Bureau of Standards is conducting extensive studies of climatic effects upon radio waves. Among these studies is the development of an exponential reference atmosphere which facilitates the estimation of refraction effects in any region for which surface weather observations are available. Worldwide maps of the mean value of the refractive index have been prepared for this purpose. In addition, a specific study has been made of radiosonde observations to determine the occurrence of groundbased radio ducts. Maximum observed incidence of ducts was determined as 13 percent in the tropics, 10 percent in the Arctic, and 5 percent in the temperate zone. Annual maximums are observed in the winter for the arctic and in the summer for the tropics.

\section{Frequency Correlation in HF Auroral Propagation}

J. W. Craig, Lincoln Laboratory, Massachusetts Institute of Technology.

Transmissions at spaced frequencies were made from Thule to Ipswich, Mass., to study the effect of disturbed conditions on the correlations of such signals. The data are now substantially reduced and some indication of the "correlation distance" in frequency obtained. Implications for possible new communication systems to operate under disturbed conditions will be discussed.

\section{Performance of the Canadian Janet B Equipment in the Auroral Zone}

J. H. Crysdale, Defence Research Telecommunications Establishment, Ottawa, Ontario

The Canadian Janet B equipment has been operated on a circuit in the auroral zone during the past year. The terminals of this circuit, which is approximately north-south and $1,000 \mathrm{~km}$ in length, are located at Edmonton and Yellowknife. The circuit is operated at two closely spaced frequencies in the vicinity of $40 \mathrm{Mc}$ and at two closely spaced frequencies in the vicinity of $50 \mathrm{Mc}$.

One of the most serious problems encountered is auroral zone blackout associated with solar flares. During July, the circuit was not usable for at least two days because of this phenomenon. From a review of the performance of other vhf circuits, it has been found that extended blackouts are by no means infrequent.

Experience to date suggests that the meteoric signal does not predominate during substantial proportions of the time. A deeply fading signal of essentially constant or slowly varying peak amplitude is often obtained and is associated with moderate error rates. Very rapidly fluctuating signals, often of considerable amplitude and probably associated with aurora, are frequently observed. With signals of this type, the error rate can be excessive, the transmissions in many cases being garbled completely.

The analysis of circuit performance is being expedited by the use of an IBM 650 computer which is programed to obtain fairly complete burst length and error rate information from the received test message tapes.

\section{A Proposal for Sweep-Frequency Soundings of the Ionosphere With Oblique Incidence at High Latitudes}

K. Davies, Central Radio Propagation Laboratory, National Bureau of Standards, Boulder, Colo.

High frequency communications (3 to $30 \mathrm{Mc}$ ) are still the most convenient for many purposes in the Arctic regions. In order to predict such characteristics as maximum usable frequency and received field strength, a knowledge of the mode structure of the received signal is desirable. The most convenient method of determining this mode structure is the sweep frequency pulse technique. This technique is generally used in vertical incidence ionospheric soundings; and hence, a knowledge of the relationship between vertical incidence and oblique incidence data is essential as a first step in the solution of this problem.

A most desirable feature in any oblique-incidence experiment is a vertical incidence ionosonde operatins at or near the midpoint of the path. This requirement is difficult to realize in the Arctic and, as far as is known, has never been achieved. However, a present there are three vertical incidence station 
located on the west coast of Greenland which are nearly equidistant. These stations are at Thule, Godhavn, and Narsarssuak. Thule and Godhavn are about $1,900 \mathrm{~km}$ apart and Godhavn is within $50 \mathrm{~km}$ of the midpoint.

The existence of these stations thus provides a unique opportunity to investigate radio propagation in a normally inaccessible area.

\section{VLF Aircraft Measurements}

R. H. Doherty, Central Radio Propagation Laboratory, National Bureau of Standards, Boulder, Colo.

Three vlf stations, NSS, NPG, and GBZ (Annapolis, Seattle, and Rugby) were monitored on a flight into the arctic region of Greenland. The flights were made in the winter, and the propagation paths were mainly nighttime paths.

Signals which had traversed the icecap were not excessively attenuated, but flights over the cap indicated a large directional effect. The directional effect has been attributed to the use of a trailing vire antenna and the large wave tilt associated with the low conductivity of the icecap. Preliminary calculations have been made in an attempt to evaluate the conductivity of the icecap. These esults are compared with Dorsey's ${ }^{1}$ values for the thysical constants of ice. The values deduced from he experiment were considerably higher, indicating nfluence of the more highly conductive ground beneath the ice.

\section{tilization of Sporadic-E Propagation in the Arctic}

R. M. Gallet, H. I. Leighton, and E. K. Smith, Central Radio Propagation Laboratory, National Bureau of Standards, Boulder, Colo.

A normal procedure in hf communication in the retic is to decrease transmission frequency during isturbed periods inasmuch as the $F_{2}$ muf is normally epressed during such times. Actually sporadic $E$ more prevalent during disturbed than quiet periods nd can be used to back up medium distance hf rcuits $(1,000$ to $2,000 \mathrm{~km}$ ) even during periods of olar blackout. However, to make the best use of ooradic $E$ the transmission frequency needs to be icreased rather than reduced.

$E$ s data obtained from the worldwide network of nosphere sounders indicate that sporadic $E$ in ie auroral zone tends to be most prevalent near 1e 100-percent isochasm (maximum occurrence of Irorae) and in the neighborhood of geomagnetic idnight. Sporadic $E$ recorded at 24 and $48 \mathrm{Mc}$ $i$ an experimental scatter circuit between Anchorage ad Barrow, Alaska, and on the College, Alaska, nosphere sounder is used to illustrate the temporal rriations of sporadic $E$ and signal levels to be pected when the Es mode of transmission is used.

N. E. Dorsey, Properties of ordinary water substance (Reinhold Publishing , New York, N.Y., 1940).

\section{Summary of Path Loss Measurements on Tropospheric Beyond-Horizon Radio Paths}

R. M. Haweкотте, Bell Telephone Laboratories, Whippany Laboratory, Whippany, N.J.

One of the most important factors that must be considered in the engineering of tropospheric beyondhorizon radio relay systems is the loss on the path between the transmitting and receiving antennas. Path loss measurements have been made on a number of paths ranging in length from about 60 to more than $800 \mathrm{mi}$. Frequencies ranging from about $100 \mathrm{Mc}$ to more than 4,000 Mc have been used on these various paths. Some of these published results of loss on paths over land, frozen sea water, and open sea water have been reduced to $800 \mathrm{Mc}$ for engineering of military communication systems in the $750-$ to $950-\mathrm{Mc}$ band. The $800-\mathrm{Mc}$ scatter loss on a path over land is in close agreement with that on a path of equal effective length over frozen sea water, but is greater than the loss on a similar path over open sea water.

\section{0-Mc Forward Scatter Results Which May Have Implication for Arctic Communication}

J. L. Heritage, Smyth Research Associates, San Diego, Calif.

In 1958 a survey was made of ionospheric signals received from a powerful $200-\mathrm{Mc}$ transmitter. On oblique transmission paths, at geomagnetic latitude about $40^{\circ}$, signals were received which resembled auroral propagation in several ways.

Great-circle ionospheric forward scatter was below detectability while rapidly fading signals with $30-\mathrm{db}$ signal-to-noise ratio were received at sites to which specular transmission was possible via $E$-layer ion columns alined with the earth's magnetic field.

These signals were named the $H_{E}$ scatter because of their connection with the earth's magnetic field at E-layer height. The system sensitivity was high-the minimum transmission loss of the $H_{E}$ scatter relative to free space loss was about $105 \mathrm{db}$. This figure is roughly comparable with the $40-\mathrm{db}$ transmission loss reported by Dyce for amateur 220-Mc auroral transmissions at higher latitude.

The $H_{E}$ scatter signals have two forms, a short burst-like form and a longer lasting form-lasting up to $20 \mathrm{~min}$. Both forms exhibit a rapid fading from the onset. The repetition rate of pulsed transmission was low-the autocorrelation function was zero for adjacent pulses.

The diurnal variation of duty cycle is similar to that found for auroral transmission. During night hours $H_{E}$ scatter duty cycle swamps the meteor burst duty cycle. Seasonal data is not yet available.

The above results suggest that at higher geomagnetic latitudes, systems of intermediate sensitivity might find $H_{E}$ scatter a useful propagation mode. It is advocated that a number of experiments be undertaken to learn more about the frequency and latitude dependence of this form of scatter. 
Results on Critical Frequency Studies for the Arctic

G. E. HILL, AVCO Research and Advanced Development Division, Wilmington, Mass.

Monthly medians of $f_{0} E$ and $f_{0} F_{2}$ for January, March, and June 1957, were collected from all available Northern Hemisphere ionospheric sounding stations. The data were arranged according to G.m.t., in 3-hr intervals, plotted on polar stereographic maps, and analyzed for isopleths of the critical frequencies (eight maps per month). Instantaneous synoptic data from the IGY network, including $f_{0} E_{\mathrm{s}}$, were handled similarly for 11 through 15 July 1957 (eight maps per day).

The monthly maps show the following: As expected the daytime $f_{0} E$ essentially follows a cosine dependence on the solar altitude. The $f_{0} F_{2}$ generally decreases toward high latitudes forming a "polar low." This polar low is more extensive in winter than summer. This polar low moves around the globe at high latitudes following the sun, the winter radius being about twice the summer radius. The high daytime winter values of $f_{0} F_{2}$ in auroral latitudes are related to the position of the polar low. Evidence of solar tidal effects is found (the polar low becomes a complex of three lows).

The synoptic series in July show that the features evident on a monthly average are present on a daily basis also. The strong regularity of the E-layer appears daily as well as monthly. The daily features of $f_{0} F_{2}$, however, show some important departures from the monthly median variations. These departures, or disturbances, have characteristic velocities ranging from about zero to several hundred $\mathrm{m} / \mathrm{sec}$. There exist preferred areas of development, but these areas are not permanent. Depressions occur at all times of the day, frequently about noon. The occurrence of sporadic $E$ in temperate latitudes is mainly in a broad belt nearly encircling the earth.

A minimum is found at early morning longitudes. At night $E_{\mathrm{s}}$ is found in northern latitudes. During the five day period wide departures from this simplified picture for $E_{\mathrm{s}}$ occur. There appears to be some correspondence between patterns of $f_{0} F_{2}$ and $E_{\mathrm{s}}$ occurrence.

The effect of the ionospheric general circulation is discussed, although no specific circulation model is presented.

\section{Planning Intersite Paths for Communications Facilities}

R. S. KinBy, Central Radio Propagation Laboratory, National Bureau of Standards, Boulder, Colo.

In selecting terminal locations for long distance communication facilities, such as scatter and hf circuits, one of the primary site conditions is to have good intersite paths to the communication relay centers. In remote areas of the world this intersiting is normally accomplished with a microwave relay operating in the 2,000- to $8,000-\mathrm{Mc}$ range. Often the sites are situated in such a way that line of site paths do not exist between the two ends. With low-powered relay equipment currently in use, this requires the siting of one or more relays at remote intermediate locations.

With higher powered relay transmitters, up to $2 \mathrm{kw}$ at 8,000 Mc, the siting requirements for intersite paths can be relaxed and nonoptical paths can conceivably be used. 'This paper presents a study of the propagation problems associated with trans mitting high-power broad-band shf signals over the horizon using diffraction and scatter modes of propagation. Particular attention is given to specia meteorological conditions prevalent in the Arctic.

\section{HF Radio Wave Absorption in Northern Latitudes}

H. Leinbach and G. C. Reid, Geophysical Institute, Uni versity of Alaska, College, Alaska.

Anomalous absorption in the lower ionosphere in the arctic regions can be classified into two types (a) aurorally-associated absorption (type II) and (b) absorption arising from ionization of the lower ionosphere by charged particles from solar flares (type III)

Aurorally-associated absorption (type II) is strong est at the southern edge of the auroral zone, i.e., ir the vicinity of $65^{\circ}$ geomagnetic latitude. Type I absorption reaches a maximum at this latitude during the post-breakup aurora (early mornin hours, local time), often reaching hourly average values in excess of 2 or $3 \mathrm{db}$ at $27 \mathrm{Mc}$. A 5-Mc wave passing once through the absorbing region at mod erate obliquity could thus suffer upwards of 200-dt attenuation, so that hf communication would becom impossible using normally attainable powers.

Type III absorption is much less frequent, bu is of considerable importance since complete absorp tion of hf waves may occur over the entire pola region north of $65^{\circ}$ geomagnetic latitude. Further more, the absorption may remain heavy for period of up to four days. Six to eight type III events pe year may be expected during the sunspot ma imum years.

The above statements are based primarily o IGY absorption data obtained in Alaska and Greer land using the cosmic noise technique at 27.6 Mc.

\section{Radio Star Scintillation Studies at College, Alask}

C. G. Littue, ${ }^{2}$ Central Radio Propagation Laborator National Bureau of Standards, Boulder, Colo.

The methods used in a study of the amplitude ar angular scintillations of the Cygnus and Cassiope

${ }^{2}$ Formerly of Geophysical Institute, University of Alaska. 
sources are briefly described. The results are presented in diagrams giving:

(1) The probability of occurrence of five different levels of scintillation activity.

(2) The probability, for each level of activity, of observing a given increase or decrease of signal strength.

(3) The probability, for each level of activity, of observing angular scintillations greater than a given value.

(4) The solar-time variation of the mean fractional deviation of power, $\frac{\overline{\Delta P} \mid}{P}$, for each source.

(5) The elevation angle dependence of $\frac{\overline{|\Delta P|}}{P}$ for each source.

The observations have led to the following conclusions relating to the College data:

$a$. The scintillation activity during $1957-58$ was some 20 times more intense than in England during $1949-51$.

$b$. The solar-time variation of scintillation activity is very much less than at temperate latitudes.

$c$. The scintillation amplitudes were largely independent of the zenith angle of the source.

$d$. The scintillation activity of the Cassiopeia source was significantly less than for the Cygnus source, owing to its large angular size.

$e$. The ionospheric blobs responsible for the scintillations are elongated along the geomagnetic field lines by a factor of about 6 . The 0.5 correlation distance transverse to the magnetic field is of the order $300 \mathrm{~m}$.

$f$. The rms deviation in electron density in the irregularities is of the order 500 electrons $/ \mathrm{cm}^{3}$ (or less) during quiet periods and is approximately 5,000 electrons $/ \mathrm{cm}^{3}$ during disturbed conditions. Values of 20,000 electrons $/ \mathrm{cm}^{3}$ would be adequate to explain the very occasional (less than $1 \%$ of the time) disappearance of the source on the interferometer recordings.

\section{Application of Data from the Vertical Incidence Ionospheric Network to Auroral Zone and Polar Cap Communication Problems}

M. E. Nason, National Bureau of Standards, North Pacific Warning Service, Anchorage, Alaska.

A network of eight NBS associated vertical sounding stations maintains a continuous schedule of ionospheric observations at auroral zone and polar cap locations ranging from Reykjavik, Iceland, to Barrow, Alaska. These data are primarily useful for long-range predictions of maximum useful frequencies. However, by telegraphic reports they can be used in the day-to-day forecasting of short term fluctuations of the MUF over important radio paths. Auroral zone and polar cap absorption effects are observable and of potential use in assessing the degree of probable disturbance.

\section{Backscattering and Propagation of Radio Waves}

L. Owren, H. Bates, and R. Hunsacker, Geophysica Institute, University of Alaska, College, Alaska.

Oblique incidence sweep-frequency backscatter sounding of the arctic ionosphere over the frequency range 1 to $25 \mathrm{Mc}$ has shown a prevalence of anomalous echoes. A direct $F$-layer echo is observed regularly and is associated with electron density irregularities at actual heights between 350 and 600 $\mathrm{km}$. Both the $1 F$ (direct) and $2 F$ (groundscatter) echoes received at College, Alaska, from the north usually connect to the extraordinary branch of the vertical incidence trace while the $2 F$ echoes from the south appear to connect to the ordinary branch. $2 \mathrm{~F}$ echoes from the north and south indicate that at times the reflecting layer is tilted $2^{\circ}$ to $3^{\circ}$.

The relative signal strength of fixed frequency pulse transmissions on 12,18 , and $30 \mathrm{Mc}$ from College, Alaska, recorded at Kiruna, Sweden, have been compared with simultaneous groundscatter echoes received at College from the polar region. Analysis for December 1958 shows that the 12 - and $18-\mathrm{Mc}$ signals are propagated by two and three-hop modes as well as a one-hop tilted layer mode. The two-hop mode is mainly a daytime mode, Alaska time, while the dominant three-hop mode occurs both day and night. Minimum received signal and polar groundscatter is observed at the time of maximum $D$-layer absorption for the outgoing radiation.

The research program is supported by the Electronics Research Directorate, Air Force Cambridge Research Center.

\section{Theory of Spread $F$ \\ Jacques Reneau, Cornell University}

On the assumption that aspect sensitivity plays a major role in the energy backscattered from ionized irregularities elongated along the earth's magnetic field, a formula for the delay time associated with a ray from the ionospheric sounder to the position of perpendicularity in the $F$-region, with allowance for refraction, has been derived.

In the hope that this mechanism may explain the phenomenon of spread $F$, computations of delay time versus frequency were carried out for several stations located at various magnetic latitudes, and the results compared to observed ionograms. It is concluded that the model does not explain arctic spread $F$ but clarifies the main features of the equatorial spread $F$.

\section{A Proposed Technique for Improving the Intelligibility of Voice Radio Transmissions in the Presence of Auroral Flutter Fading}

O. G. Villard, Jr., and K. C. YeH, Radio Propagation Laboratory, Stanford University, Stanford, Calif.

It would appear to be possible to make a significant improvement in the intelligibility of voice radio transmissions garbled by auroral flutter fading, by 
transmitting the voice at a higher-than-normal rate, followed by an equal slow-down at the receiving end of the circuit. This has the effect of reducing the effective speed at which the individual frequency components of the voice signal are made to fade as a consequence of transmission via a disturbed ionosphere. A slow-down in fading speed can be expected to improve intelligibility because present evidence suggests that the voice quality of amplitudemodulated transmissions falls off very rapidly when the average carrier fading speed becomes higher than roughly $10 \mathrm{cps}$.

Since the increased transmission speed requires an increase in bandwidth and a consequent reduction in received signal-to-noise ratio, the method will be useful only when adequate signal-to-noise ratios are initially present. The required equipment is relatively simple and adaptable to existing communication systems.

\section{Some Sporadic Phenomena of the Auroral Zone}

E. S. Warren, Defence Research Telecommunications Establishment, Shirley Bay, Ontario

Some effects of the sporadic ionization revealed by ionograms in the auroral zone are reviewed. The oblique incidence equivalents of spread $F$, polar spurs, and forked records are illustrated by oblique sounding records. The influence of these phenomena on hf point-to-point communication is discussed. Suggestions are made for the improvement of longterm predictions, in particular for the calculation of the MUF and the LUF and for handling the statistical variations. For the operators problem it is suggested that information from a few obliqueincidence sounders be disseminated as it is produced.

\section{Observations on Some Low Frequency Propagation Paths in Arctic Areas}

A. D. Watt, E. L. Maxwell, and E. H. Whelan, Central Radio Propagation Laboratory, National Bureau of Standards, Boulder, Colo.

The very low ground conductivities encountered in arctic area, and the particular ionospheric conditions prevailing at high latitude, can lead to rather unusual radiation and propagation conditions. In order to determine the magnitude of these effects, field intensities from transmitters located in the Labrador and Greenland areas were measured both on the surface of the earth and during several aircraft flights over this area.
Under conditions where the initial portion of the propagation path is across icecap or permafrost, the attenuation observed is very great, and when the propagation path extends out over sea water, the field intensity recovery taking place after the coastline is crossed is very marked. Estimates of skywave field intensity appear to agree with the observed results provided the radiated field pattern is suitably modified by the antenna cutback factor which accounts for the presence of a finitely conducting curved earth. These vertical patterns based on work by Wait, along with the field intensity flight data, indicate that the siting of low frequency stations several miles or more inland in arctic regions may cause a great increase in total transmission path loss.

Initial Investigation of Techniques for Prediction of Short-Term $f_{0} F_{2}$ Variations in the Higher Latitudes

J. M. Weldon, National Bureau of Standards, North Atlantic Warning Service, Fort Belvoir, Va.

This paper discusses initial attempts by the North Atlantic Radio Warning Service to develop techniques for predicting high frequency radio propagation conditions over specific high latitude transmission paths. A description of the radio forecasting methods used in the general area forecast service currently provided is presented. It is suggested that while the service now offered is quite reliable over the general North Atlantic Path for which it is primarily intended, i.e., New York to London, Washington to Paris, etc., there is need for the inclusion of a specific path forecasting mechanism designed for operational use in the higher latitude circuits which are more susceptible to geomagnetic disturbance. The problem is approached by studying the ionosphere along the particular paths with the aim of finding useful relationships that can be applied toward predicting radio quality and proper frequency ranges to employ for daytime, nighttime, and transition periods. Correlative studies between $F_{2}$ layer critical frequencies at probable control points of several paths and solar activity indices, magnetic indices, and radio quality data are described generally and conclusions are drawn based on the results. Large negative deviations are readily associated with predictable magnetically active periods. However, to date few encouraging relationships have been found involving magnetically quiet period $f_{0} F_{2}$ variations. Future experiments are suggested to test further the feasibility of specific path forecasting.

Boulder, Colo.

(Paper 64D1-41) 